\title{
Anatomical dead space, ventilatory pattern, and exercise capacity in chronic heart failure
}

\author{
A L Clark, T P Chua, A J S Coats
}

\begin{abstract}
Background-Patients with chronic heart failure have an excessive ventilatory response to exercise, characterised by an increase in the slope of the relation between ventilation and carbon dioxide production ( $\dot{\mathrm{V}} / \dot{\mathrm{V}} \mathrm{CO}_{2}$ slope). Patients have an altered respiratory pattern with an increased respiratory rate $(f)$ at a given tidal volume (VT), which may result in increased anatomical dead space ventilation.
\end{abstract}

Methods-The ventilatory responses in 88 patients with chronic heart failure and 43 age matched controls during maximal incremental treadmill exercise were analysed. Peak oxygen consumption $\left(\dot{\mathbf{V}} \mathrm{O}_{2}\right), \dot{\mathrm{V}} \mathrm{E} / \dot{\mathrm{CO}}_{2}$ slope, and the slope of the relation between $f$ and $V T$ were derived. Anatomical dead space was estimated from a standard formula and anatomical dead space ventilation calculated.

Results-Peak $\dot{V}_{2}$ was greater (mean (SD)) (33.2 (8.5) v 19.4 (6.7) $\mathrm{ml} / \mathrm{min} / \mathrm{kg}$; $P<0.001)$ and the $\dot{V} E / \dot{V} O_{2}$ slope lower in the controls $(25.96(4 \cdot 16) v 35 \cdot 14(9 \cdot 80) ; P$ $<0.001)$. During matched submaximal exercise VT was higher $(1.97(0.92) v 1.68$ $(0.62) 1 ; P<0.05)$ and $f$ lower in the controls $(18.23(6.48) \quad v \quad 24 \cdot 28(7.58) ; \quad P<$ $0.001)$. At peak exercise there was no difference in $f$, but $V T$ was higher in the controls $(2.66(0.97) \quad v \quad 1.90(0.61) \quad 1 ; P<$ $0 \cdot 001)$. The VT/f slope was the same (0.04 $(0.04))$ in both groups. The intercept of the relation was greater for the control group (1.31 (1.28) v $0.59(0.83) ; \quad P<$ $0 \cdot 001)$. Anatomical dead space ventilation was lower in the controls at submaximal work load (4.17 (1.56) v $5.58(1.93) \mathrm{l} / \mathrm{min}$; $P<0.001)$. At peak exercise anatomical dead space ventilation was the same in both groups, but was lower expressed as a percentage of total $\dot{V} E$ in the control group (9.8 (3.3) $v 13.5(4.0) ; P<0.001)$. There were weak relations within the heart failure group alone between VT/f slope and peak $\dot{\mathrm{Vo}}_{2}$ and $\mathrm{VE} / \dot{\mathrm{V}} \mathrm{Co}_{2}$ slope.

Conclusions-The relation between anatomical dead space ventilation and $\dot{V} \mathbf{E} / \dot{V} \mathrm{CO}_{2}$ slope is expected: as $\mathrm{f}$ increases, so do $\dot{\mathrm{V}} / \mathbf{\mathrm { V }} \mathrm{CO}_{2}$ slope and anatomical dead space ventilation. The VT/f slope was the same in patients with chronic heart failure and controls, so change in respiratory pattern cannot explain the increase in $\dot{V} E / \dot{V C O}_{2}$ slope. The stimulus causing the increased $f$ has yet to be identified.
(Br Heart f 1995;74:377-380)

Keywords: chronic heart failure; dead space; ventilatory pattern; exercise capacity

The excessive ventilatory response to exercise in chronic heart failure is well characterised by an increase in the slope relating minute ventilation $(\dot{V} E)$ to carbon dioxide production $\left(\dot{\mathrm{V}} \mathrm{CO}_{2}\right)$. This slope is described by a linear regression function with an $r$ value in excess of 0.9 in almost all cases. The increase in the $\dot{\mathrm{V}} / \dot{\mathrm{V}} \mathrm{CO}_{2}$ slope is closely related to the degree of exercise limitation as characterised by a reduction in peak oxygen consumption (peak $\left.\dot{\mathrm{VO}}_{2}\right) .{ }^{12}$ The cause of the increased ventilation is not definitively established, although an increase in dead space ventilation has been proposed. ${ }^{3-5}$

One possible contribution to an increase in dead space ventilation is that of anatomical dead space (ADS). ${ }^{6}$ Patients with heart failure have an abnormal breathing pattern: at any given $\dot{V} E$, tidal volume (VT) is smaller and respiratory frequency $(f)$ is increased. ${ }^{37}$ As a result, ADS, even if considered fixed in absolute terms, is ventilated more often, and as a proportion of total ventilation, anatomical dead space ventilation is increased.

We wanted to explore the possible contribution of the altered ventilatory pattern to the increased $\dot{\mathrm{V}} / \dot{\mathrm{V}} \mathrm{CO}_{2}$ slope, using the slope of the relation between respiratory rate and tidal volume $^{8}$ to describe the ventilatory pattern.

\section{Patients and methods}

We examined the responses to exercise of 88 patients with chronic heart failure of mean (SD) age $58.6(11.6)$ years and compared them with 43 matched controls of mean (SD) age $54.6(10.5)$ years. The table gives patient details. Patients were referred for exercise testing as part of their routine assessment. The controls were volunteers from among hospital staff, and in addition some were recruited from among men attending for routine medicals arranged by their companies. These controls gave fully informed signed consent before exercise testing.

Heart failure was diagnosed on the basis of decreased exercise capacity in the presence of impaired left ventricular dysfunction as shown by echocardiograms, radionuclide ventriculography scans, or cardiac catheterisation. All patients were stable for a minimum of 6 weeks before exercise testing. None was oedematous 
Characteristics of patients and controls

\begin{tabular}{|c|c|c|c|}
\hline & $\begin{array}{l}\text { Patients } \\
(n=88)\end{array}$ & $\begin{array}{l}\text { Controls } \\
(n=43)\end{array}$ & $p$ value \\
\hline $\begin{array}{l}\text { Mean (SD) age (years) } \\
\text { Mean (SD) weight (kg) }\end{array}$ & $\begin{array}{l}58 \cdot 6(11 \cdot 6) \\
78 \cdot 6(14 \cdot 2)\end{array}$ & $\begin{array}{l}54 \cdot 6(10 \cdot 5) \\
79 \cdot 5(13 \cdot 7)\end{array}$ & $\begin{array}{l}\text { NS } \\
\text { NS }\end{array}$ \\
\hline \multicolumn{4}{|l|}{ Diagnosis } \\
\hline Dilated cardiomyopathy & 41 & & \\
\hline Ischaemic heart disease & 47 & & \\
\hline $\begin{array}{l}\text { Mean (SD) left ventricular } \\
\text { ejection fraction (\%) }\end{array}$ & $28 \cdot 2(14 \cdot 2)$ & & \\
\hline Mean (SD) cardiothoracic ratio & $0.57(0.07)$ & & \\
\hline \multicolumn{4}{|l|}{ Drugs* } \\
\hline Frusemide & $81 \cdot 8(72 \cdot 7)$ & & \\
\hline \multicolumn{4}{|l|}{ Angiotensin converting } \\
\hline enzyme inhibitor & 65 & & \\
\hline Warfarin & 23 & & \\
\hline Digoxin & 20 & & \\
\hline \multirow{2}{*}{\multicolumn{4}{|c|}{$\begin{array}{l}\text { Amioaarone } \\
\text { New York Heart Association }\end{array}$}} \\
\hline & & & \\
\hline I & 16 & & \\
\hline II & 23 & & \\
\hline III & 35 & & \\
\hline IV & 14 & & \\
\hline \multicolumn{4}{|l|}{ Mean $(\mathrm{SD})$ peak $\dot{\mathrm{V}}_{2}$} \\
\hline$(\mathrm{ml} / \mathrm{min} / \mathrm{kg})$ & $19 \cdot 1(6 \cdot 7)$ & $33 \cdot 2(8 \cdot 5)$ & $<0.001$ \\
\hline Mean (SD) exercise time (s) & $499(210)$ & $837(185)$ & $<0.001$ \\
\hline Mean (SD) $\mathrm{VE} / \mathrm{VCO}_{2}$ slope & $35 \cdot 14(9 \cdot 80)$ & $25 \cdot 96(4 \cdot 16)$ & $<0.001$ \\
\hline
\end{tabular}

*The mean (SD) daily dose of frusemide is given; other values refer to the number of patients taking each drug. Peak $\mathrm{VO}_{2}$, maximurn rate of oxygen consumption; $\mathrm{V} \mathrm{E} / \dot{\mathrm{V}} \mathrm{CO}_{2}$ slope, slope of the relation between ventilation and carbon dioxide production; NS, not significant.

nor limited by symptoms of angina or claudication. Patients with intercurrent illness or documented lung pathology were excluded.

Participants undertook incremental treadmill exercise tests using a Bruce protocol modified by the addition of a "stage 0 " at onset-that is $3 \mathrm{~min}$ exercise at $1.61 \mathrm{~km} / \mathrm{h}$ with a 5\% gradient. Exercise to exhaustion was encouraged. Participants breathed through a one way valve connected to a respiratory mass spectrometer (Amis 2000; Odense, Denmark). Metabolic gas exchange $\left(\dot{V}_{2}, \dot{V} \mathrm{CO}_{2}\right)$ and $\dot{V} E$ were measured on line every $10 \mathrm{~s}$ using the inert gas dilution method. ${ }^{9}{ }^{10}$ In addition, the mass spectrometer allowed continuous monitoring of fractional carbon dioxide concentration at the mouth. Breathing rate was measured from the capnograph, and VT was calculated from $\dot{\mathrm{VE}}$ and $\mathbf{f}$.

ADS was estimated from the standard formula, $\mathrm{ADS}=$ weight $\times 2 \cdot 2+$ age. ${ }^{11} \mathrm{ADS}$ ventilation (VADS) was calculated from ADS $\times \mathbf{f}$, and was also expressed as a percentage of $\dot{\mathrm{V}} \mathrm{E}$ (ADS.f $/ \dot{\mathrm{V}} \mathrm{E} \times 100 \%$ ). The values recorded were averages of the last $30 \mathrm{~s}$ of each stage of exercise and at peak exercise.

The $\dot{\mathrm{V}} \mathrm{E} / \dot{\mathrm{V}} \mathrm{CO}_{2}$ slope and peak $\mathrm{Vo}_{2}$ were calculated for each test. The slope of the relation between VT and $\mathbf{f}$ was also derived. After exercise the patient was asked for the dominant symptom at peak exercise. The first response was recorded. Quoted results for matched submaximal exercise were taken from the end of stage 1 of exercise.

Results are expressed as means (SD). Between groups comparisons were made with unpaired Student's $t$ test; within group comparisons were made with paired $t$ tests. Correlations were calculated by the least squares method. The null hypothesis was rejected where $P<0.05$.

\section{Results}

The table gives the exercise results. The
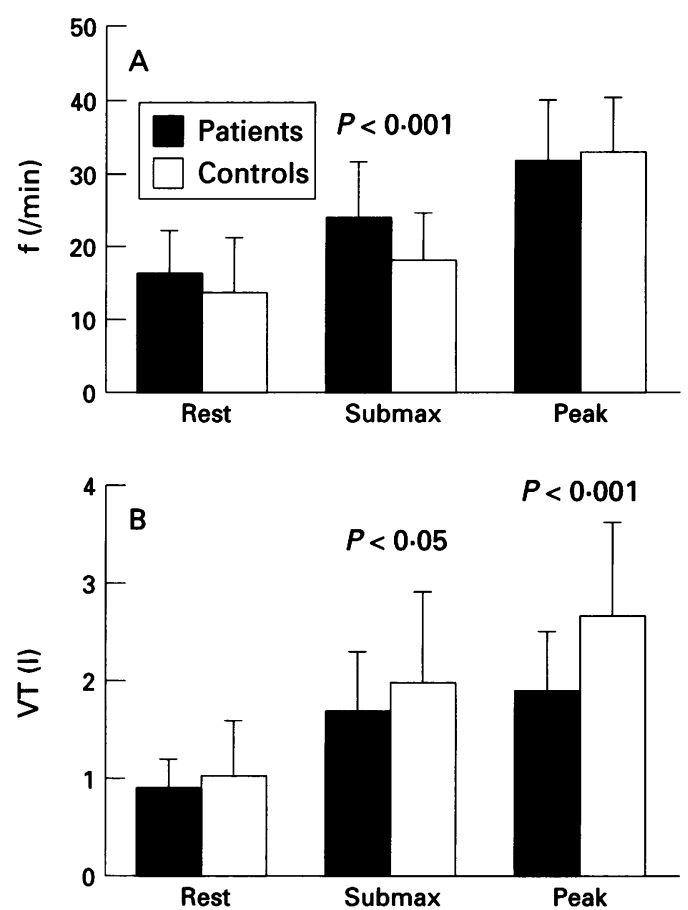

Figure 1 (A) Respiratory frequency $(f)$ and $(B)$ tidal volume $(V T)$ at rest, during matched submaximal exercise, and peak exercise in patients with chronic heart failure and controls. Bars are standard deviations.

regression coefficient for the $\dot{\mathrm{V}} \mathrm{E} / \dot{\mathrm{V}} \mathrm{CO}_{2}$ relation was greater than 0.94 in all cases. As previously reported, ${ }^{12}$ there was a negative relation between peak $\dot{\mathrm{VO}}_{2}$ and $\dot{\mathrm{VE}} / \dot{\mathrm{V}} \mathrm{CO}_{2}$ slope $(r=-0.59 ; \mathrm{P}<0.001)$ in patients with heart failure.

Figure 1 shows the VT and $\mathbf{f}$ at rest, matched submaximal exercise, and peak exercise in patients with heart failure and controls. At matched work loads during exercise VT was greater and the $f$ slower in the controls.
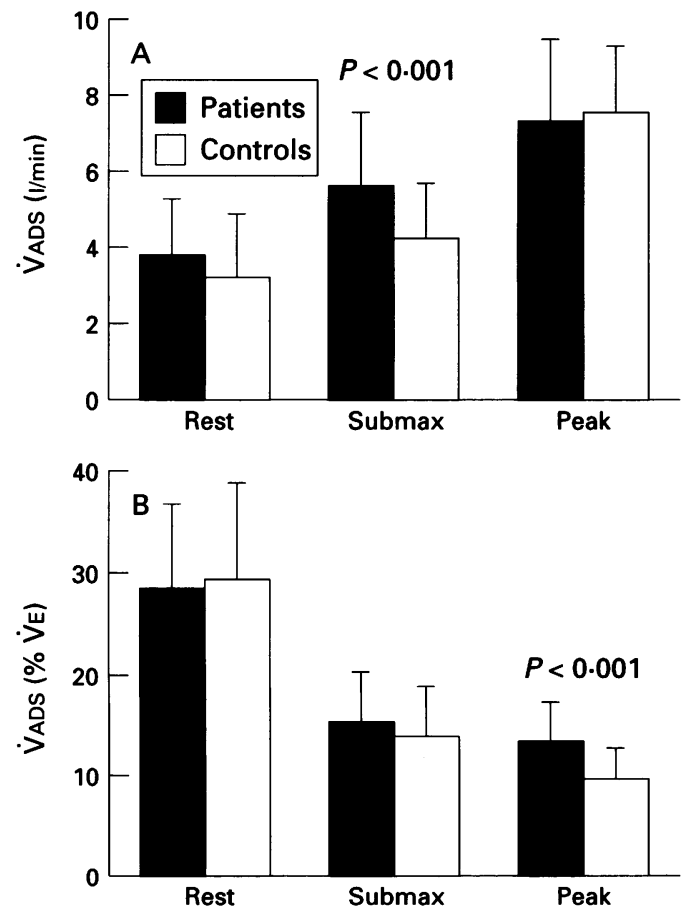

Figure 2 Anatomical dead space ventilation ( $\left.\dot{V}_{A D S}\right)$ in. (A) l/min and as a proportion of total minute ventilation $\left(\dot{V}_{E}\right)(B)$ in patients with chronic heart failure and controls. 
Figure 3 Relation between tidal volume (VT) and respiratory frequency Values are means $(95 \%$ confidence intervals (CI)). Bars are $95 \%$. (f) in patients with chronic heart failure and controls.

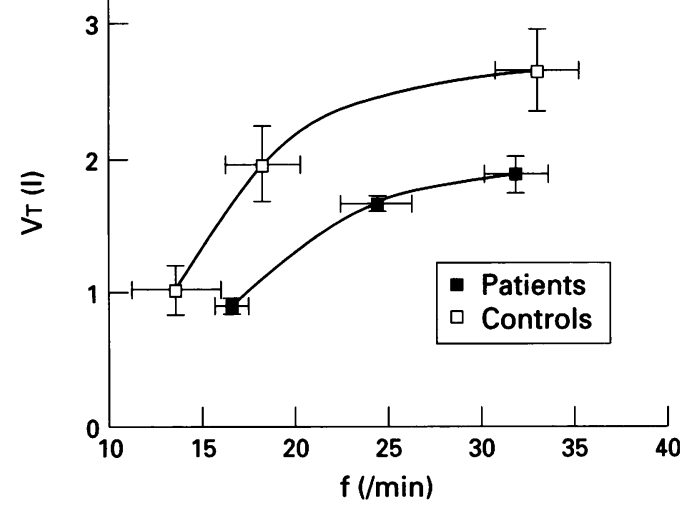

At peak exercise both groups had similar respiratory rates, but the control group has a much higher VT and hence VE.

ADS was estimated as $231.6(33.4)$ in patients with heart failure and $229 \cdot 4(28 \cdot 3)$ in the controls $(P=N S)$. Figure 2 shows VADS values. As $\mathbf{f}$ is greater in heart failure at submaximal exercise, so is VADS, although as a percentage of $\dot{V} E, \dot{V} A D S$ is not significantly different from controls, reflecting the greater total $\dot{V} E$ as submaximal work loads in chronic heart failure. As peak $\mathbf{f}$ is similar in patients and controls, peak VADS is also the same in both groups; as total $\dot{V} E$ is greater in the controls, then VADS as a percentage of total ventilation is higher in patients with heart failure.

The VT/f relation was much less strong than that between $\dot{\mathrm{V}} \mathrm{E}$ and $\dot{\mathrm{V}} \mathrm{CO}_{2}$. The mean (SD) correlation coefficient was $0.55(0.26)$ for patients with heart failure and $0.44(0.33)$ for the controls. The mean slope was the same $(0.04(0.04)$ in both groups. The intercept on the $y$ axis (that is, VT when $f$ is zero) was 0.59 $(0 \cdot 83) 1$ in the patients with chronic heart failure and $1.31(1.28)$ in the controls $(\mathrm{P}<0.001)$.

We could identify a break point in the $\dot{\mathrm{V}} \mathrm{T} / \mathbf{f}$ relation in only four patients and in two controls, unlike the situation reported by

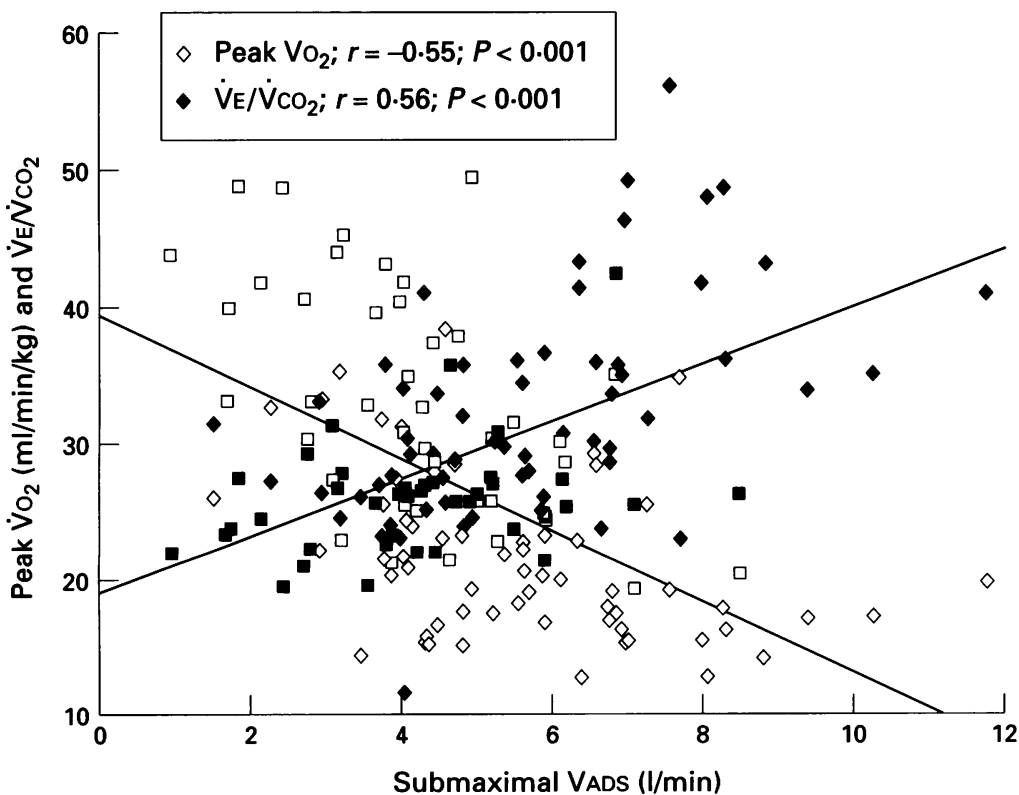

Figure 4 Submaximal anatomical dead space ventilation (VADS) as a "predictor" of peak oxygen consumption (peak $\dot{V} \mathrm{O}_{2}$ ) and the $\dot{V} \mathrm{E} / \dot{\mathrm{V}} \mathrm{CO}_{2}$ slope. Open symbols refer to peak $\dot{V} \mathrm{O}_{2}$ and filled symbols to the $\dot{V} \mathrm{E} / \dot{\mathrm{V}} \mathrm{CO}_{2}$ slope. Diamonds refer to patients and squares to controls.
Yokoyama et $a l,{ }^{8}$ who reported a point at which $\mathbf{f}$ started to increase relative to $\mathrm{VT}$, which corresponded to the onset of dyspnoea. The slope of the VT/f relation was the same in the patients stopped by breathlessness $(70.5 \%)$ and in those stopped by fatigue $(29.5 \%)(0.03(0.03)$ in both subgroups). Figure 3 shows the data plotted for the two groups, which may give the misleading impression of such a break point; this plot shows that the VT/f relation is similar in patients and controls $(0.04(0.04)$ in each group), but is displaced downwards and to the right in heart failure.

\section{CORRELATES OF VENTILATORY RESPONSE}

There was a weak relation between the VT/f slope and both peak $\dot{\mathrm{VO}}_{2}(r=0.29 ; \mathrm{P}=$ $0.006)$ and $\dot{\mathrm{V}} / \dot{\mathrm{V}}_{2}$ slope $(r=-0.30 ; \mathrm{P}=$ $0.005)$. There was no correlation between peak $\dot{\mathrm{V}} \mathrm{ADS}$ and either peak $\dot{\mathrm{V}} \mathrm{O}_{2}$ or $\dot{\mathrm{V}} / \mathrm{V}_{\mathrm{CO}}$ slope in patients with heart failure. Expressed as a proportion of $\dot{V} E$, there was a significant negative relation with peak $\dot{\mathrm{V}}_{2}(r=-0.52 ; \mathrm{P}$ $<0.001)$. Submaximal VADS correlated with peak $\dot{\mathrm{V}} \mathrm{O}_{2}$ and $\dot{\mathrm{V}} / \dot{\mathrm{V}} \mathrm{CO}_{2}$ slope (fig 4).

\section{Discussion}

The pathophysiological mechanism underlying the increased $\mathrm{VE} / \mathrm{V} \mathrm{CO}_{2}$ slope in chronic heart failure remains unexplained. In the cardiological literature, reference to the alveolar ventilation equation-that is $\dot{\mathrm{V}} \mathrm{E} / \dot{\mathrm{V}} \mathrm{CO}_{2}=$ $863 /\left(\mathrm{PaCO}_{2} \times(1-\mathrm{VD} / \mathrm{VT})\right.$, where $\mathrm{PaCO}_{2}$ is arterial carbon dioxide tension, $\mathrm{VD} / \mathrm{VT}$ is dead space as a fraction of VT, and 863 is a constant, is taken as evidence that the cause of the increased $\dot{\mathrm{V}} / \dot{\mathrm{V}} \mathrm{CO}_{2}$ slope in the face of near normal arterial blood gas tensions ${ }^{1213}$ must be increased dead space. ${ }^{3-5} \mathrm{~A}$ major contribution to such an increase in dead space ventilation could arise from an increase in VADS consequent on a change in ventilatory pattern. If this was the case, then it might be anticipated that the relation between VT and $\mathbf{f}$ would be shallower in patients with chronic heart failure with an increase in VंE being met predominantly by a rise in $\mathbf{f}$ rather than $\dot{V}$. It might be thought that the slope of this relation would correlate with exercise capacity and $\dot{V} \mathrm{E} / \dot{\mathrm{V}} \mathrm{CO}_{2}$ slope.

In the present study we have shown no difference between the VT/f slope in patients with chronic heart failure and controls. There were weak relations within the heart failure group alone between $\mathrm{VT} / \mathrm{f}$ slope and peak $\dot{\mathrm{VO}}_{2}$ and $\dot{\mathrm{V}} / \dot{\mathrm{V}} \mathrm{CO}_{2}$ slope. This relation disappeared when all participants were analysed together. The intercept value was higher for the controls, indicating that VT was about 0.721 greater in controls, but there was considerable overlap between the two groups. The VT/f slope was the same regardless of symptoms at peak exercise, which fits with our earlier suggestion that breathlessness and fatigue represent a single physiological process, perhaps not related to ventilatory abnormality. ${ }^{14}$

We found that both groups stopped exercising when the peak $f$ was about the same. 
Patients with chronic heart failure reached this point at a lower $\mathrm{VT}$, and thus with a higher VADS as a proportion of $\dot{V} E$. Conversely, at matched work load, as ventilation was greater in the patients with heart failure, the greater minute $\dot{V}$ ADS was a similar percentage of total VंE. The relation between dead space during submaximal exercise and exercise capacity is expected; submaximal VADS increases as $\mathbf{f}$ increases. As $\mathbf{f}$ increases at a given level of $\dot{\mathrm{V}} \mathrm{CO}_{2}$, so does $\dot{\mathrm{V}} \mathrm{E} / \dot{\mathrm{V}} \mathrm{CO}_{2}$; given the negative relation that exists in heart failure between $\dot{\mathrm{V}} / \mathrm{V} \mathrm{CO}_{2}$ slope and peak $\dot{\mathrm{VO}}_{2}$, it is inevitable that $\dot{\mathrm{V}} \mathrm{ADS}$ and peak $\dot{\mathrm{VO}}_{2}$ will correlate.

These results suggest that VADS is not an important contributor to the increased ventilatory response to exercise in chronic heart failure. Changes in VADS may result from a change in ventilatory pattern, but the VT/f slope was the same in patients with heart failure and controls. We have previously shown that there is no relation between altered respiratory pattern and the $\dot{\mathrm{V}} \mathrm{E} / \dot{\mathrm{V}} \mathrm{CO}_{2}$ slope in normal controls. ${ }^{15}$ Rather than the increase in $\dot{\mathrm{V}} \mathrm{ADS}$ leading to an increased $\dot{\mathrm{V}} \mathrm{E} / \dot{\mathrm{V}} \mathrm{CO}_{2}$ slope, both can be thought of as arising as a consequence of an alteration in ventilatory pattern. The nature of the stimulus causing the increased $\mathbf{f}$ has yet to be identified.

1 Buller NP, Poole-Wilson PA. Mechanism of the increased ventilatory response to exercise in patients with chronic heart failure. $B r$ Heart $\mathcal{f} 1990 ; 63: 281-3$.

2 Davies SW, Emery TM, Watling MIL, Wannamethee G, Lipkin DP. A critical threshold of exercise capacity in the ventilatory response to exercise in heart failure. $\mathrm{Br}$ Heart $\mathcal{F}$ 1991;65:179-83.

3 Sullivan MJ, Higginbotham MB, Cobb FR. Increased exercise ventilation in patients with chronic heart failure: intact ventilatory control despite haemodynamic and pulmonary abnormalities. Circulation 1988;77:552-9.

4 Myers J, Salleh A, Buchanan N, Smith D, Neutel J, Bowes E, Froelicher VF. Ventilatory mechanisms of exercise intolerance in chronic heart failure. Am Heart $f$ intolerance in

5 Metra M, Dei Cas L, Panina G, Visioli O. Exercise hyperventilation chronic congestive heart failure and its relation to functional capacity and hemodynamics. $\mathrm{Am} \mathcal{f}$ Cardiol 1992;70:622-8.

6 Weber KT, Kinasewitz GT, Janicki JS, Fishman AP. Oxygen utilisation and ventilation during exercise in patients with chronic cardiac failure. Circulation 1982;65:1213-23.

7 Rubin SA, Brown HV. Ventilation and gas exchange during exercise in severe chronic heart failure. Am Rev Respir Dis 1984;129(suppl): S63-4.

8 Yokoyama H, Sato H, Hori M, Takeda H, Kamada T. A characteristic change in ventilation mode during exertional dyspnoea in patients with chronic heart failure. Chest 1994;106:1007-13.

9 Lipkin DP, Perrins J, Poole-Wilson PA. Respiratory gas exchange in the assessment of patients with impaired ventricular function. Br Heart f 1985;54:321-8.

10 Davies N, Denison DM. Measurement of metabolic gas exchange and minute volume by mass spectrometry alone. Respir Physiol 1979;36:261-7.

11 Cotes JE. Lung function. 4th ed. Oxford: Blackwell Scientific Publications, 1979:244.

12 Rubin SA, Brown HV, Swan HJC. Arterial oxygenation and arterial oxygen transport in chronic myocardial failure at rest, during exercise and after hydralazine treatment. Circulation 1982;66:143-8.

13 Clark AL, Coats AJS. Usefulness of arterial blood gas estimations during exercise in patients with chronic heart failure. Br Heart $\mathcal{f} 1994 ; 71: 528-30$

14 Clark AL Sparrow $\pi$, Coats AJS. Muscle fatigue and dyspnoea in chronic heart failure: two sides of the same dyspnoea in chronic heart failure:
coin? Eur Heart $\mathcal{F} 1994$. In press.

15 Clark AL, Coats AJS. Effects of induced changes in anatomical dead space ventilation on the relationship between ventilation and carbon dioxide production in normal man. Eur $\mathcal{F}$ Clin Invest 1993;23:428-32. 